\title{
A single-cell resolution gene expression atlas of the larval zebrafish brain
}

Inbal Shainer*1, Enrico Kuehn*1, Eva Laurell ${ }^{1}$, Mariam Al Kassar ${ }^{1}$, Nouwar Mokayes ${ }^{1}$, Shachar Sherman ${ }^{1}$, Johannes Larsch ${ }^{1}$, Michael Kunst ${ }^{1,2}$, Herwig Baier $^{1 * *}$

\author{
*Co-first author \\ ** Corresponding author
}

${ }^{1}$ Max Planck Institute of Neurobiology, Martinsried. Current address: Max Planck Institute for Biological Intelligence, in foundation, Martinsried, Germany

${ }^{2}$ Allen Institute for Brain Science, Seattle, WA 98109, USA

\begin{abstract}
The advent of multimodal brain atlases promises to accelerate discoveries in neuroscience by offering in silico queries of cell types, connectivity and gene expression in regions of interest. We employed multiplexed fluorescent in situ RNA hybridization chain reaction (HCR) to generate expression maps for an initial set of 200 marker genes across the larval zebrafish brain. The data were registered to the Max Planck Zebrafish Brain (mapzebrain) atlas, thus allowing co-visualization of gene expression patterns, single-neuron tracings, transgenic lines and anatomical segmentations. Additionally, brain activity maps of freely swimming larvae were generated at single-cell resolution using HCR labeling of the immediate-early gene cfos and integrated into the atlas. As a proof of concept, we identified a novel class of cerebellar eurydendroid cells that express calb2a, project to the hypothalamus and are activated in animals that have recently ingested food. Thus, a cellular-resolution gene expression atlas will not only help with rapid identification of marker genes for neuronal populations of interest, but also bridge the molecular and circuit levels by anchoring genetic information to functional activity maps and synaptic connectivity.
\end{abstract}




\section{Introduction}

Development and function of neural circuits depend on the spatiotemporal dynamics of differential gene expression across the brain. Particular classes of genes play prominent roles in organizing the layout of the nervous system and may serve as markers of cell-type identity and/or function. These include genes whose protein products directly influence cell-cell interactions and local properties of the synaptic network, and those that regulate the expression of other genes to determine cell fate, diversification, morphology and connectivity of neurons. Often the corresponding RNAs are expressed in a region- and cell-type specific fashion. Another class of important marker genes encode functional determinants, e. g., neurotransmitter-synthesizing enzymes, ion channels, synaptic machinery components, and neuropeptides; the presence of the corresponding proteins provides information about physiological properties of the expressing neurons and tends to be not cell-type specific (except for neuropeptides). Visualizing the expression of these markers in an atlas format offers a glimpse into the molecular and cellular composition of neural circuitry. Such an atlas then allows researchers to select markers for labeling and manipulating neurons of interest. Moreover, co-visualizing many of these markers offers a holistic view of the genetic architecture of the brain and may reveal general organizing principles.

The most prominent attempt at visualizing brain-wide transcript expression, while preserving spatial layout of the tissue, is probably the Allen Brain Atlas project, which published the results of RNA in situ hybridizations for thousands of genes in tissue sections, first in mouse (Lein et al., 2007) and later in human (Hawrylycz et al., 2012). These pioneering studies, together with both prior and more recent work with similar aims (e. g., Gong et al., 2003; Ortiz et al., 2020; M. Zhang et al., 2021), are of immense value for the research community. The resulting resources are routinely consulted by experimenters seeking to corroborate hypotheses and identify genetic markers for neuronal subpopulations of interest.

Atlases of the nervous system have also been devised for other model organisms, although, to our knowledge, not yet for RNA in situ hybridization patterns to faithfully map the endogenous gene expression. The nervous system of the nematode worm Caenorhabditis elegans has been charted in unsurpassed detail (Cook et al., 2019). Most recently, a strain of C. elegans has been developed by genetic engineering in which each of its 302 neurons is identifiable in one animal by a combination of fluorescent proteins (Yemini et al., 2021). This multicolor atlas enables in vivo interrogation of the spatial arrangement of identifiable neurons and serves as a 
convenient readout of the effects of developmental perturbations on cell fate and positioning (Yemini et al., 2021). In the fruitfly Drosophila melanogaster, the "virtual fly brain browser" (Milyaev et al., 2012) and the "fruit fly brain observatory" (Ukani et al., 2019) offer standardized neuroanatomical frames in which thousands of transgene expression patterns are co-registered, generating a light-microscopic mesoscale connectome. In the zebrafish Danio rerio, histological brain atlases have been available for some time (adult: Kenney et al., 2021, Wullimann et al., 1996; embryo/larva: Mueller and Wullimann, 2015), as well as atlas databases of hundreds of transgenic lines and immunostainings, such as "ViBE-Z” (Ronneberger et al., 2012), “Z-brain” (Randlett et al., 2015) and the "Zebrafish Brain Browser" (Tabor et al., 2019). The Max Planck Zebrafish Brain ("mapzebrain") atlas (Kunst et al., 2019) at https://fishatlas.neuro.mpg.de/ is a multimodal digital atlas of the 6 days postfertilization (6 dpf) larval brain, integrating data portals for transgenic lines, histological stains, and expertly curated neuroanatomical regions, as well as a growing number (currently ca. 4,300) of single-cell morphologies. These datasets are all registered into the same spatial coordinate system, the so-called 'standard brain' (Kunst et al., 2019). The atlas web interface offers refined visualization and animation tools, as well as options for downloading original data for offline analyses. Here we set out to add RNA fluorescent in situ hybridization (FISH) patterns to the mapzebrain atlas. Single-cell resolution was achieved by hybridization chain reaction (HCR), a spatial transcriptomics method that is highly sensitive, specific and multiplexable, allowing visualization of several RNA species in one specimen with different probe-specific fluorophores (Choi et al., 2018). Moreover, as a powerful tool for recording activity hotspots across the brain, we have devised an HCR FISH protocol for detecting cfos RNA following various sensory stimulations and behavioral tasks. All the data are publicly available and free to download through the mapzebrain website (https://fishatlas.neuro.mpg.de/). This new resource, which can be easily expanded in the future by community contributions, offers convenient web-based access to markers of neuronal subpopulations and paves the way for a genetic analysis of circuit architecture in this widely used vertebrate model.

\section{Results and Discussion}

\section{Pipeline for HCR FISH labeling and registration to the mapzebrain atlas}


Recent developments of FISH techniques, such as RNAscope, MERFISH and HCR (Chen et al., 2015; Choi et al., 2018; Wang et al., 2012), offer single RNA molecule detection and multiplexing in vivo. We chose HCR, because the staining protocol is easily implemented in larval and juvenile fish (Choi et al., 2018; Kappel et al., 2021) and is suitable for registration into a common 3D reference (Kappel et al., 2021; Lovett-Barron et al., 2020). HCR technology enables multiplexed FISH of up to 5 probe sets per round of staining with different fluorophores (Choi et al., 2018). To scale up the number of RNA species mapped, we tested two approaches: either multi-round HCR FISH by stripping the HCR signal by DNAse I treatment and re-staining of the same sample (Lovett-Barron et al., 2020; Xu et al., 2020); or labeling of different genes in different specimens and computational registering into a common coordinate system. Although the former strategy gives theoretically unlimited information about co-expression in specific single cells, we decided against it mainly for two reasons: First, we noticed that iterative rounds of stripping and re-labeling lead to a cumulative deformation of the tissue, which made alignment of the volume across staining rounds computationally challenging and prone to error. Second, the initial set of markers is, of course, not final, as new markers or better probes are certain to become available in the future. Thus, to allow for seamless addition of new data to the atlas, as well as for future improvements to the protocol, we chose to generate expression maps from single rounds of HCR and computational co-registration into a standard brain.

To enable co-alignment of different brains, we carried out HCR FISH stainings in the background of the Tg(elavl3:H2b-GCaMP6s) transgenic line, in which nuclear-localized GCaMP6s is expressed in almost all neurons. We generated an averaged brain template of the Tg(elavl3:H2b-GCaMP6s) line using the advanced normalization tool (ANTs) toolkit (Avants et al., 2011; Suppl. Figure 1) and calibrated a registration protocol (see Methods; Suppl. Movie 1). We then acquired FISH data for more than 200 genes (Suppl. Table 1), which were previously identified as distinct, often cell-type specific markers in retina, tectum and diencephalon (Kölsch et al., 2021; Raj et al., 2020; Sherman et al., 2021; Shainer et al., manuscript in preparation). This initial set of markers includes genes encoding transcription factors, cell-surface and secreted molecules, enzymes involved in transmitter synthesis and transport, neuropeptides, calcium-binding proteins, and other factors (Figure 1; Suppl. Table 1).

For each marker gene, we labeled and imaged three $6 \mathrm{dpf}$ fish, which we registered to the standard brain and averaged (Figure 1; see Methods). We multiplexed two genes per sample (Suppl. Table 1), and acquired the 
data at single-cell resolution, revealing the number of cells expressing a particular gene per region of interest (ROI), as well as any overlapping expression (Figure 2). All The FISH patterns of individual marker genes, including the average and the individual fish, are publicly accessible through the latest version of mapzebrain at https://fishatlas.neuro.mpg.de/ (Figure 1).

\section{FISH image co-registration with other mapzebrain data modalities}

Co-registration of the new FISH dataset with existing mapzebrain datasets frequently suggested spatial overlaps. For example, after registration, the expression of aldhla2 partially overlapped with the pattern of the transgenic enhancer trap line mpn321Gt in the pretectum (Suppl. Figure 2). To verify this in silico overlap of data acquired by different procedures (i. e., live imaging, immunostaining and FISH), we carried out aldhla2 FISH labeling in larvae expressing the mpn321Gt transgene and indeed found co-expression of the two markers in individual cells in the pretectum (Suppl. Figure 2). This finding highlights the potential to identify and confirm marker genes for cell populations of interest via rapid FISH labeling, and demonstrates the robustness and reproducibility of our digital image registration pipeline. 
bioRxiv preprint doi: https://doi.org/10.1101/2022.02.11.479024; this version posted February 11,2022 . The copyright holder for this

preprint (which was not certified by peer review) is the author/funder, who has granted bioRxiv a license to display the preprint in perpetuity. It is made available under aCC-BY-NC 4.0 International license.
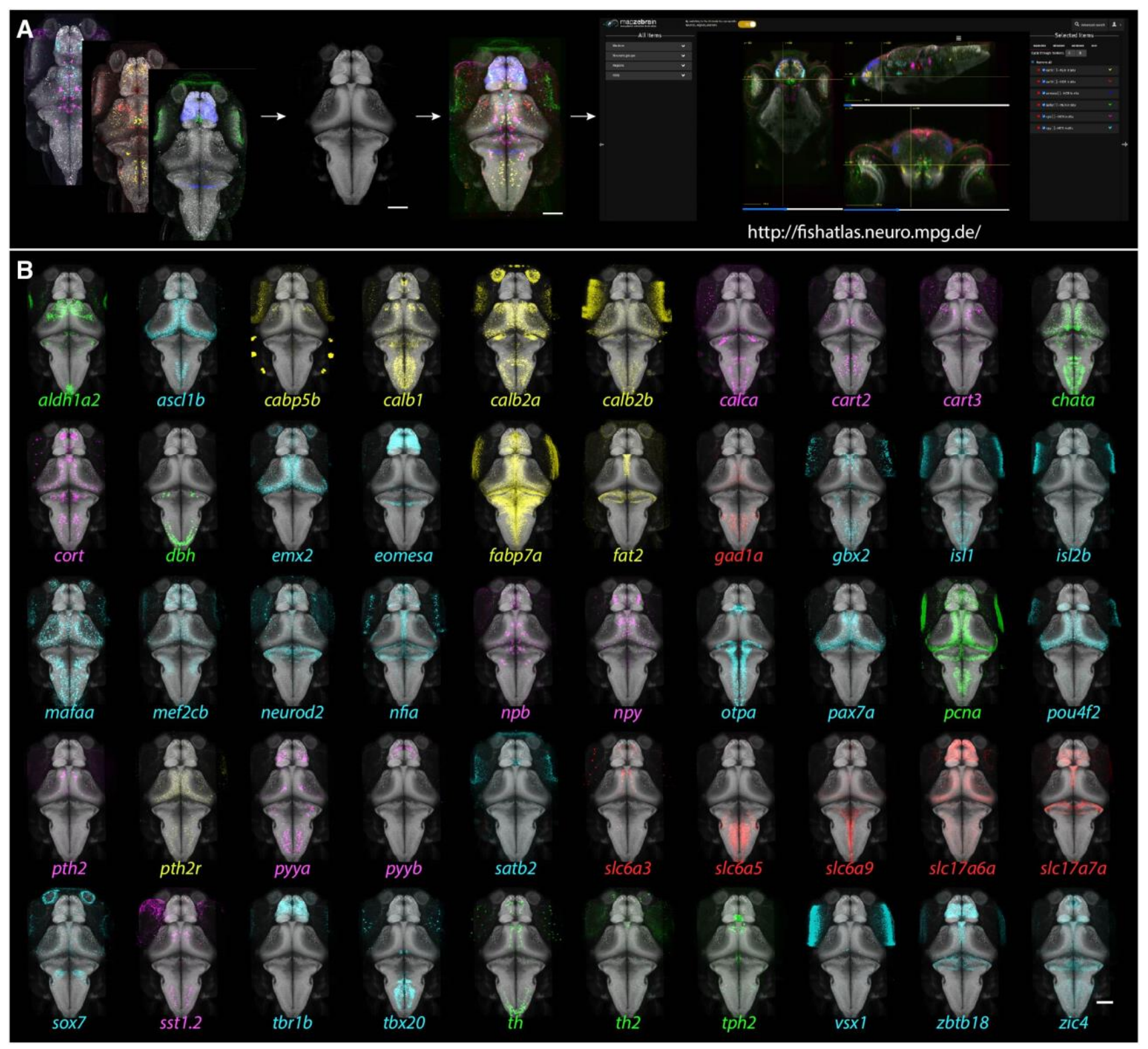

Figure 1. Gene expression atlas of the larval zebrafish brain.

A. Multiplexed FISHs were performed on $6 \mathrm{dpf}$ Tg(elavl3:H2b-GCaMP6s) fish. The GCaMP6s signal was utilized to align the images to the reference brain, and the aligned imaged were then uploaded to the mapzebrain atlas. Scale bar $=100 \mu \mathrm{m}$. B. 3D projections of 50 selected FISH images, registered into the standard brain. Color coding: green - enzymes; cyan transcription factors; red - neurotransmitter transporters; magenta - neuropeptides; yellow - miscellaneous other. Scale $\operatorname{bar}=100 \mu \mathrm{m}$. 

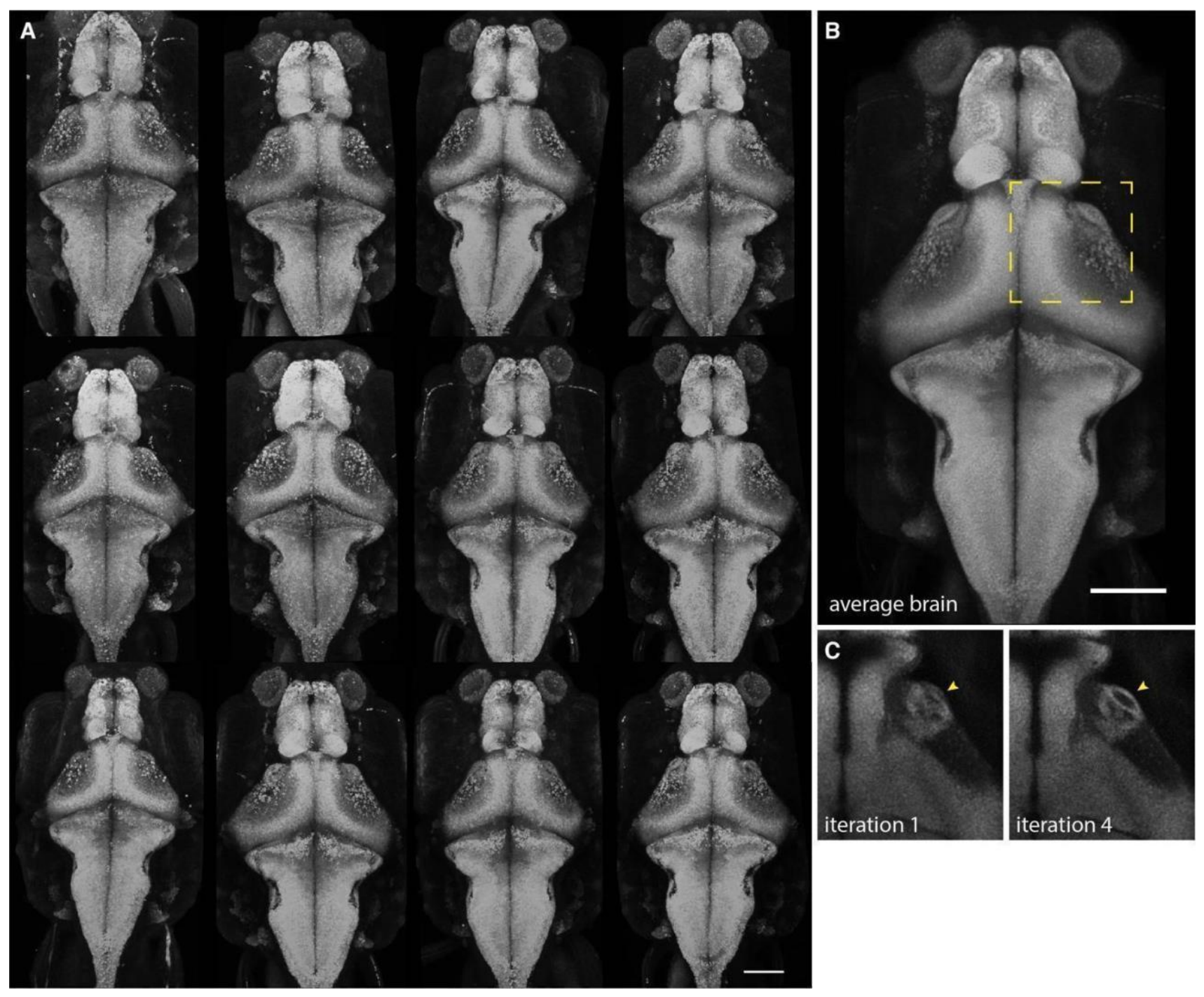

\section{Supplementary Figure 1. Generation of the FISH reference brain.}

A. 3D projections of $12 \mathrm{Tg}$ (elavl3:H2b-GCaMP6s) age-matched (6 dpf) larvae. B. An unbiased average template was generated based on the individual images using ANTs iterative template construction. C. Template resolution was markedly improved over the 4 iteration rounds, as can, for example, be observed by the clear borders of arborization field 7 (arrowheads). Scale bars $=100 \mu \mathrm{m}$.

\section{Suppl. Movie 1. Accurate registration of FISH images into the mapzebrain atlas.}

An example of a single FISH sample after registration into the standard brain. Single focal planes of the GCaMP6s channel, spanning different depths (z planes) from ventral to dorsal, are shown. Scale bar $=100 \mu \mathrm{m}$. 
bioRxiv preprint doi: https://doi.org/10.1101/2022.02.11.479024; this version posted February 11, 2022. The copyright holder for this

preprint (which was not certified by peer review) is the author/funder, who has granted bioRxiv a license to display the preprint in perpetuity. It is made available under aCC-BY-NC 4.0 International license.
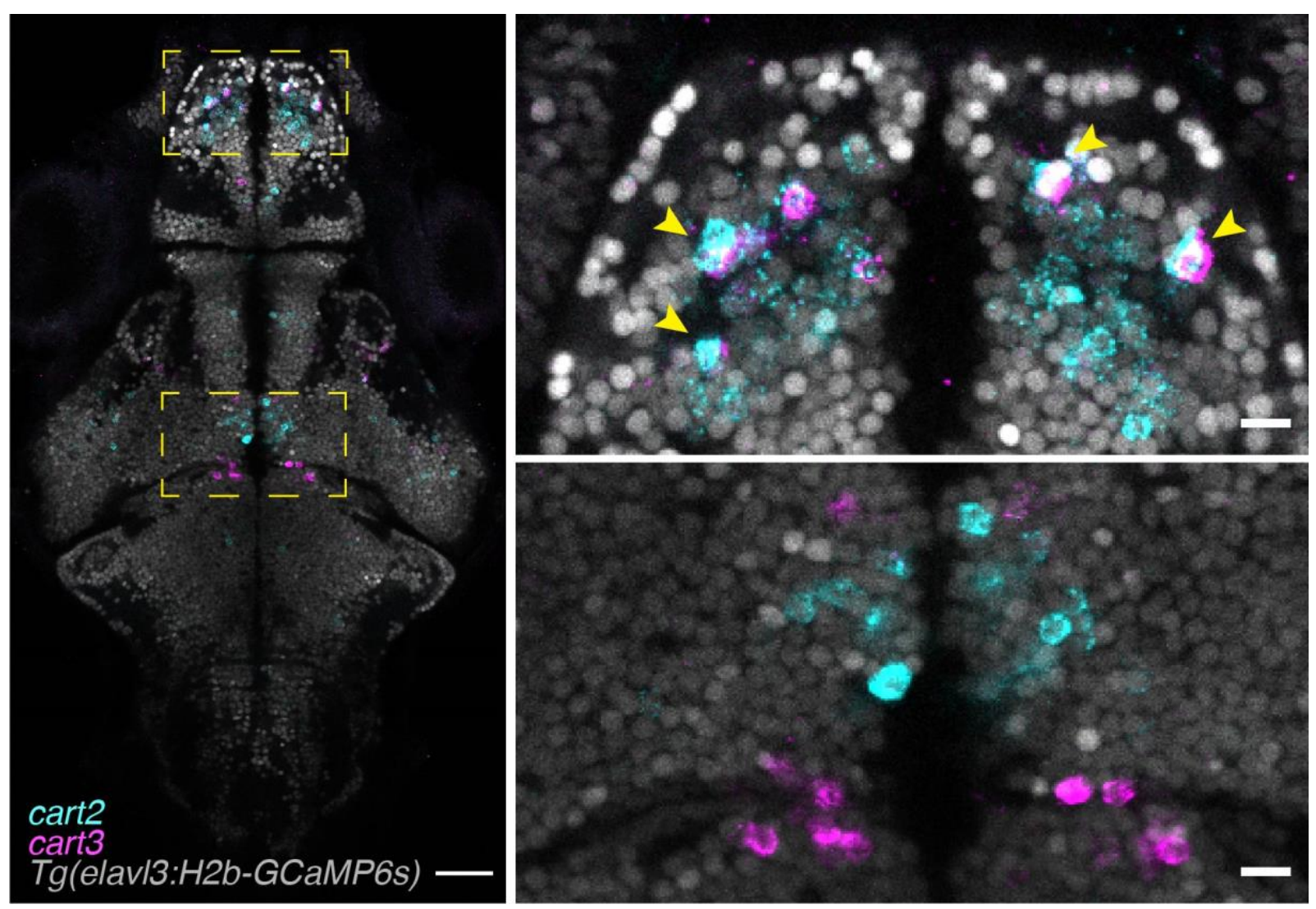

Figure 2. Multiplexed HCR in situ labeling of single cells.

Single focal plane of a multiplexed HCR labeled fish. The endogenous expression of Tg(elavl3:H2b-GCaMP6s) labels neuronal nuclei and can be used to segment single neurons and to identify whether, or not, genes are co-expressed (arrowheads). Left scale bar $=100 \mu \mathrm{m}$, right scale bars $=10 \mu \mathrm{m}$. 

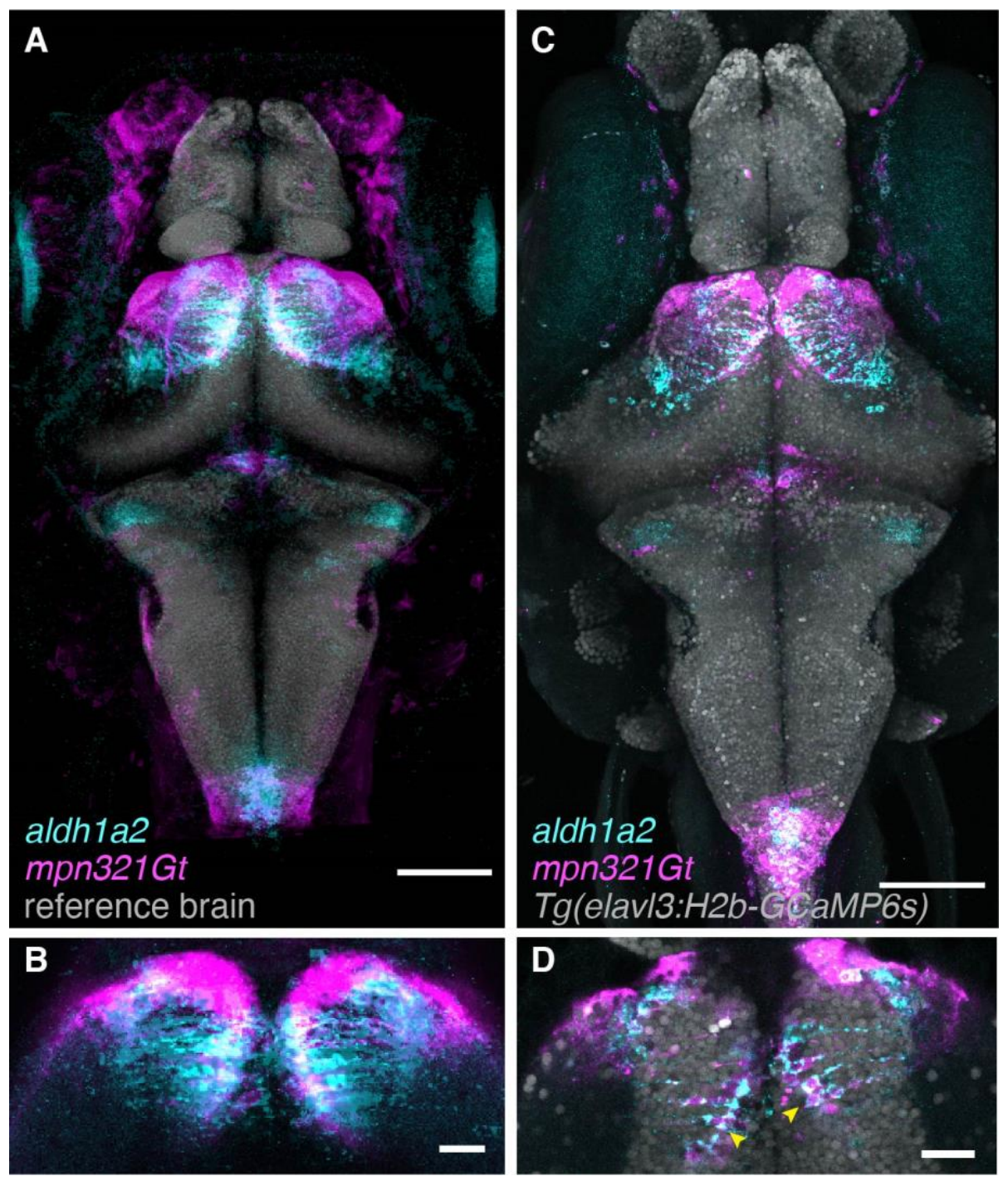

Supplementary Figure 2. Registration correspondence between FISH and transgenic lines.

A. 3D projection of aldhla2 FISH and mpn321Gt transgenic line after registration to the atlas. Scale bar $=100 \mu \mathrm{m}$. B. Single focal plane of the pretectum region of A. shows an in silico overlap between aldhla2 and mpn321Gt. Scale bar = $25 \mu \mathrm{m}$. C. 3D projection of aldh1a2 FISH performed on a larva expressing both mpn321Gt and Tg(elavl3:H2b-GCaMP6s) transgenes. Scale bar $=100 \mu \mathrm{m}$. D. Single focal plane of the pretectum region of C. shows that aldhla2 is truly co-expressed together with mpn321Gt transgene in pretectum cells (arrowheads). Scale bar $=25 \mu \mathrm{m}$.

\section{Generating $c$ fos brain activity maps of freely swimming fish in diverse behavioral paradigms}

To expand the capabilities of our gene expression resource, we challenged the fish larvae in sensory or behavioral paradigms and carried out FISH staining of cfos (Figure 3; Suppl. Movie 2). cfos is an immediate early gene, expressed in neurons after prolonged depolarization, and is commonly used as a marker for neuronal activity (Herrera and Robertson, 1996; Kovacs, 2008). We exposed two groups of larval zebrafish to high temperature $\left(32^{\circ} \mathrm{C}\right)$ or low temperature $\left(22^{\circ} \mathrm{C}\right)$. Another group was allowed to hunt prey for 40 minutes. Other larvae were held for 40 minutes on a black, or a white, background. Still others were subjected for $40 \mathrm{~min}$ to a 
drifting, black-and-white grating, which induced an optomotor response (OMR; Neuhauss et al., 1999; Orger et al., 2000), or to a repeatedly looming black disk on a white background, thus evoking a series of visual escape responses (Temizer et al., 2015). Two groups were exposed either to an asymmetric light source, which evoked phototaxis (Brockerhoff et al., 1995; Orger et al., 2004), or to the alarm substance, 'Schreckstoff', which was extracted from fish skin (see Methods).

For each condition, we imaged, registered and averaged six fish larvae. Qualitative inspection of the $c f o s$ FISHlabeled areas revealed different activity hotspots (Figure 3; Suppl. Movie 2). Activity maps largely confirmed previously published imaging studies of embedded animals (Chen et al., 2018; Chia et al., 2019; Semmelhack et al., 2014; Temizer et al., 2015; Wee et al., 2019). For example, in larvae that were hunting prey, we observed strong cfos labeling in the anterior optic tectum and retinal arborization field 7 (AF7; Figure 3; Suppl. Movie 2), which were extensively described for their involvement in prey detection and prey capture initiation in both embedded and freely swimming fish (Antinucci et al., 2019; Cong et al., 2017; Gahtan et al., 2005; Semmelhack et al., 2014; Z. Zhang et al., 2021).

Additionally, our approach revealed activity hotspots, which had not been reported previously. For example, in larvae that were hunting prey, we observed cfos labeling in cells surrounding the cerebellar neuropil (Figure 3; Suppl. Movie 2). Activity in this area seems to be specific to situations in which the animal is allowed to freely hunt and appears in conjunction with ingestion of food (Cong et al., 2017; Z. Zhang et al., 2021). We conclude that single-cell resolution $c f o s$ maps can help to localize brain activity in the context of unrestrained behavior.

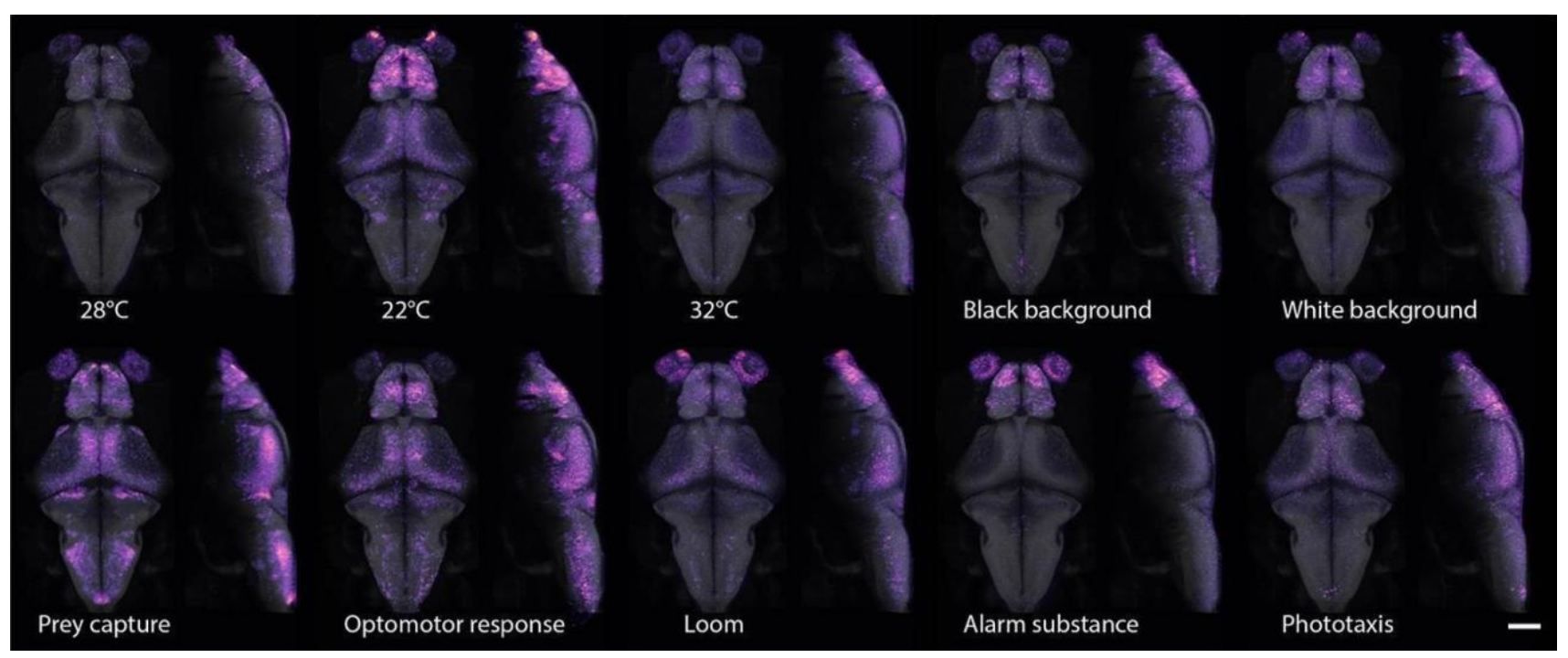

Figure 3. cfos brain activity maps of freely swimming fish. 
3D projections of $c f o s$ FISH labeled areas of neuronal activity during behavior. Dorsal (left) and lateral (right) views are shown for each experimental condition. For interactive viewing, see mapzebrain atlas at https://fishatlas.neuro.mpg.de/. Scale bar $=100 \mu \mathrm{m}$.

\section{Suppl. Movie 2. Brain activity maps of freely swimming fish.}

Single focal planes spanning different depths (z planes) from ventral to dorsal. Several key anatomical areas are labeled. Scale bar $=100 \mu \mathrm{m}$. For interactive viewing, see mapzebrain atlas at https://fishatlas.neuro.mpg.de/.

\section{Discovery of behaviorally relevant circuits using $c$ fos FISH}

To explore how the $c f o s$ activity maps can be used for circuit analysis, we closely investigated the cerebellar area activated during hunting behavior. Interrogation of the mapzebrain atlas for marker genes expressed in this location, revealed that this region contains neurons labeled by calb2a. We verified this overlap by multiplexed HCR FISH of $c f o s$ and calb2a (Figure 4).

Next, we drew a 3D ROI ('volume of interest') encompassing the cerebellar cfos-labeled region to query the database for individual morphologically reconstructed neurons from the mapzebrain atlas. We focused on neurons that had their somas within the ROI (Figure 4). Our search yielded 32 neurons, which we hierarchically clustered using the NBLAST algorithm (Costa et al., 2016) into 4 morphological types: one with stereotypical Purkinje cell morphology projecting to the octavolateral nucleus, and 3 eurydendroid cell types (Figure 4D). One group of eurydendroid cells projected to the dorsal zone of the periventricular hypothalamus (Figure 4D, cluster 4), an area involved in satiety response (Wee et al., 2019). Strikingly, this brain region was also strongly stained for $c f o s$ expression during prey capture behavior (Suppl. Movie 2). We speculate that $c a l b 2 a^{+}$ eurydendroid cells, which are activated immediately after ingestion, contribute to regulation of satiety, perhaps through connectivity to the hypothalamus. This circuit may be conserved: Eurydendroid cells are considered homologous to the deep cerebellar nuclei in mammals (Bae et al., 2009; Heap et al., 2013). In humans and mice, deep cerebellar nuclei are activated after ingestion of food and may signal satiety (Low et al., 2021). While an experimental test of this hypothesis is beyond the scope of the current work, the newly discovered correspondence illustrates the power of integrating gene expression, functional cfos labeling, transgene and single-cell reconstructions in a multimodal atlas resource. 

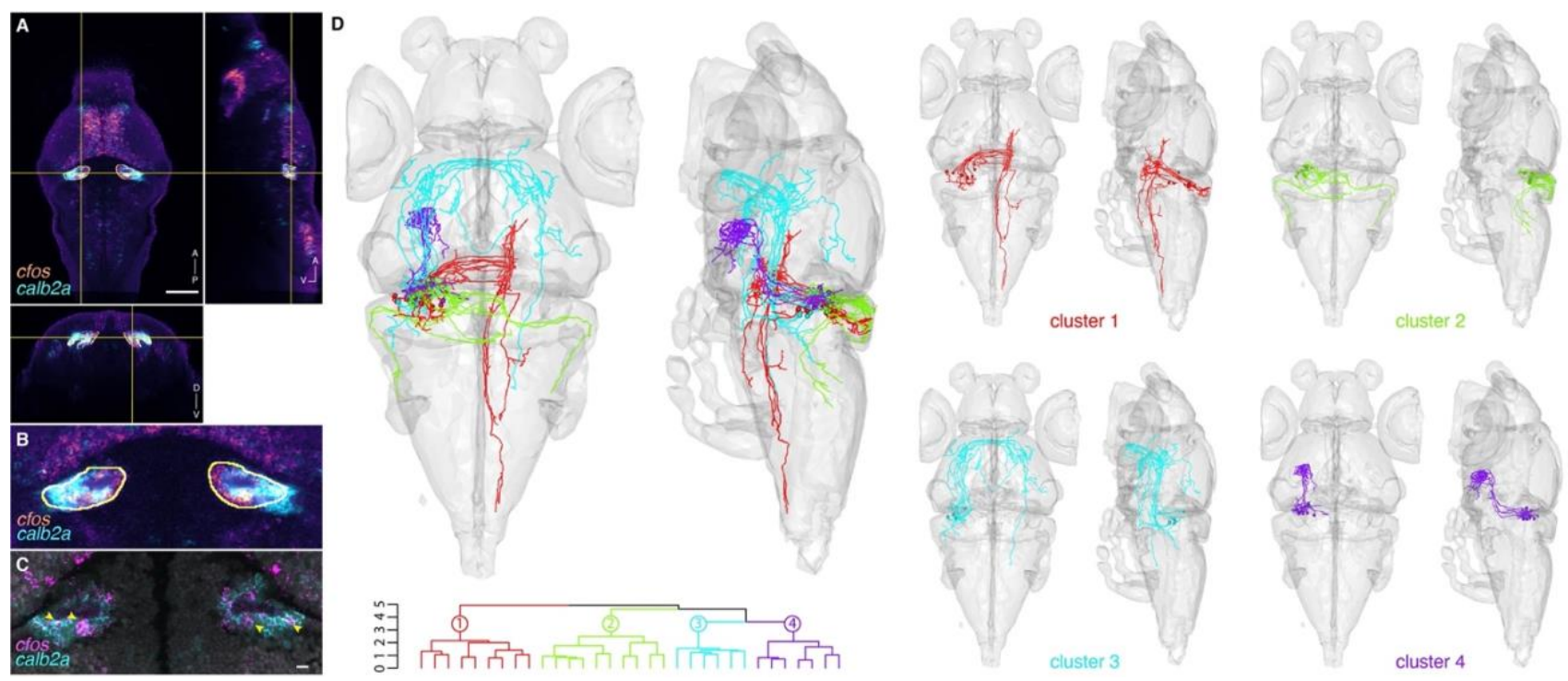

Figure 4. Marker gene expression and hypothetical connectivity of cerebellum neurons involved in prey capture.

A. Orthogonal views of the $c f o s$ prey capture brain activity map with the registered calb2a FISH. An ROI is drawn around the $c f o s$ positive cerebellar area (yellow). Scale bar $=100 \mu \mathrm{m}$. Abbreviations: A-anterior; D-dorsal; P-posterior, V-ventral. B. Enlargement of the cfos-positive cerebellar area. Possible co-labeling was identified between the registered cfos and calb2a data. C. Multiplexed FISH of calb2a and cfos verified the suggested co-labeling (arrowheads), and therefore revealing a marker gene for the cerebellar neurons involved in prey capture. A single focal plane of an individual larva is shown. Scale bar $=10 \mu \mathrm{m}$. D. The ROI drawn in A. was used to search for single neurons whose somas are within the ROI. 32 neurons were identified, mirrored onto the left hemisphere and hierarchically clustered according to their morphology. One cluster of Purkinje cells (cluster 2), was identified as well as 3 clusters of eurydendroid cells, with projections to the contralateral hindbrain (cluster 1), to the contralateral retinal arborization field 7 (AF7) and tectum through the postoptic commissure (cluster 3) and to the hypothalamus (cluster 4).

\section{Conclusion}

We have presented here an essential addition to the brain atlas resources for larval zebrafish: whole-brain, single cell-resolution gene expression data for an initial set of 200 markers, co-registered in a single standard brain volume with thousands of single-neuron tracings, hundreds of transgenic lines and over 100 expertly curated anatomical segmentations. We further show, as a proof of concept, that such multimodal datasets, in combination with cfos mRNA brain activity maps, enable the discovery of behaviorally relevant neuronal subpopulations and pathways. The web interface of mapzebrain gene expression resource offers advanced computational, visualization and downloading options and can be seamlessly expanded in the future by community contributions to the atlas. 


\section{Methods}

\section{Zebrafish husbandry and maintenance}

Adult zebrafish of the TLN strain were kept at $28^{\circ} \mathrm{C}$ with a day/night cycle of $14 / 10$ hours, $\mathrm{pH}$ of $7-7.5$, and a conductivity of $600 \mu \mathrm{S}$. All the experiments were performed on Tg(elavl3:H2b-GCaMP6s) larvae produced by natural matings. Larvae were raised until 6 days post fertilization (dpf) at $28^{\circ} \mathrm{C}$ in Danieau's solution in petri dishes. The larvae were treated with PTU starting 24 hours post fertilization to prevent pigmentation. For $c f o s$ experiments, $T g($ elavl3:H2b-GCaMP6s) larvae in the TLN background, carrying the mitfa mutation and lacking melanin pigment, were used without PTU treatment. The animal experiments were performed under the regulations of the Max Planck Society and the regional government of Upper Bavaria (Regierung von Oberbayern), approved protocols: ROB-55.2-2532.Vet_02-20-11, ROB-55.2-2532.Vet_02-21-93, 55.2- ROB2532.Vet_02-20-183, ROB-55.2-2532.Vet_02-19-16.

\section{HCR FISH staining}

HCR reagents, including probes, hairpins and buffers, were purchased from Molecular Instruments (Los Angeles, California, USA). The staining was performed according to a modified protocol of the "HCR RNAFISH protocol for whole-mount zebrafish embryos and larvae" provided by Molecular Instruments (Choi et al., 2018). $T g($ elavl3:H2b-GCaMP6s) positive larvae were anesthetized in $1.5 \mathrm{mM}$ tricaine and fixed with ice-cold 4\% PFA/DPBS overnight at $4{ }^{\circ} \mathrm{C}$ with gentle shaking. The following day, larvae were washed 3 times for 5 min with DPBST (1x Dulbecco's PBS $+0.1 \%$ Tween-20) to stop fixation, followed by a short 10 min treatment with ice-cold $100 \%$ Methanol at $-20^{\circ} \mathrm{C}$ to dehydrate and permeabilize the tissue samples. Next, rehydration was performed by serial washing of 50\% $\mathrm{MeOH} / 50 \%$ DPBST and 25\% MeOH/75\% DPBST for 5 min each and finally 5 x 5 min in DPBST. 10-12 larvae were transferred into a $1.5 \mathrm{ml}$ Eppendorf tube and pre-hybridized with pre-warmed hybridization buffer for $30 \mathrm{~min}$ at $37^{\circ} \mathrm{C}$. Probe solution was prepared by transferring 2 pmol of each HCR probe set ( $2 \mu \mathrm{l}$ of $1 \mu \mathrm{M}$ stock) to $500 \mu \mathrm{l}$ of hybridization buffer at $37^{\circ} \mathrm{C}$ (for $c f o s$ experiments, $4 \mu \mathrm{l}$ of $1 \mu \mathrm{M}$ probe stock were used.) The hybridization buffer was replaced with probe solution, and the samples were incubated for $12-16$ hours at $37^{\circ} \mathrm{C}$ with gentle shaking. To remove excess probe, larvae were washed $4 \mathrm{x}$ 15 min with $500 \mu$ l of pre-warmed probe wash buffer at $37^{\circ} \mathrm{C}$. Subsequently, larvae were washed $2 \times 5 \mathrm{~min}$ with 
$5 \mathrm{x}$ SSCT $(5 \mathrm{x}$ sodium chloride sodium citrate $+0.1 \%$ Tween-20) buffer at room temperature. Next, preamplification was performed by incubating the samples in $500 \mu 1$ of amplification buffer for 30 min at room temperature. Separately, $30 \mathrm{pmol}$ of hairpin h1 and $30 \mathrm{pmol}$ of hairpin h2 were prepared by snap-cooling $10 \mu \mathrm{l}$ of $3 \mu \mathrm{M}$ stock by incubating the hairpins in $95^{\circ} \mathrm{C}$ for 90 seconds, and cooling down to room temperature in a dark environment. After cooling down for $30 \mathrm{~min}$, hairpin solution was prepared by transferring the h1 and h2 hairpins to $500 \mu \mathrm{l}$ amplification buffer. The pre-amplification buffer was removed, and the samples were incubated in the hairpin solution for 12-16 hours in the dark at room temperature. Excess hairpins were washed the next day $3 \times 20$ min using $5 \mathrm{x}$ SSCT at room temperature. Larvae were then long-term stored at $4^{\circ} \mathrm{C}$ in $5 \mathrm{X}$ SSCT until imaging.

\section{Imaging}

Samples were embedded in 2\% low-melting agarose in 1x DPBS (Dulbecco's PBS) and imaged with a Zeiss LSM700 confocal scanning microscope (upright), equipped with a 20x water immersion objective. Z-stacks, composing 2 tiles, were taken and stitched to produce a final image with size of 1039 x 1931 pixel (463.97 x $862.29 \mu \mathrm{m}, 1 \mu \mathrm{m}$ in $\mathrm{z})$.

\section{Generation of reference brain and image registration and averaging}

All the image registrations and averaging procedures were performed using Advanced Normalization Tools (ANTs) (Avants et al., 2011), which were previously calibrated and used for generation of zebrafish average brain images (Kunst et al., 2019; Marquart et al., 2017). Twelve transgenic fish expressing the transgenes Tg(elavl3:H2b-GCaMP6s) and Tg(elavl3:lynTag-RFP) were fixed and underwent the entire HCR buffers procedure, but without the usage of any probes or hairpins, and imaged as described. The images were used to generate an unbiased average template brain by running the following ANTs command on the GWDG computing cluster:

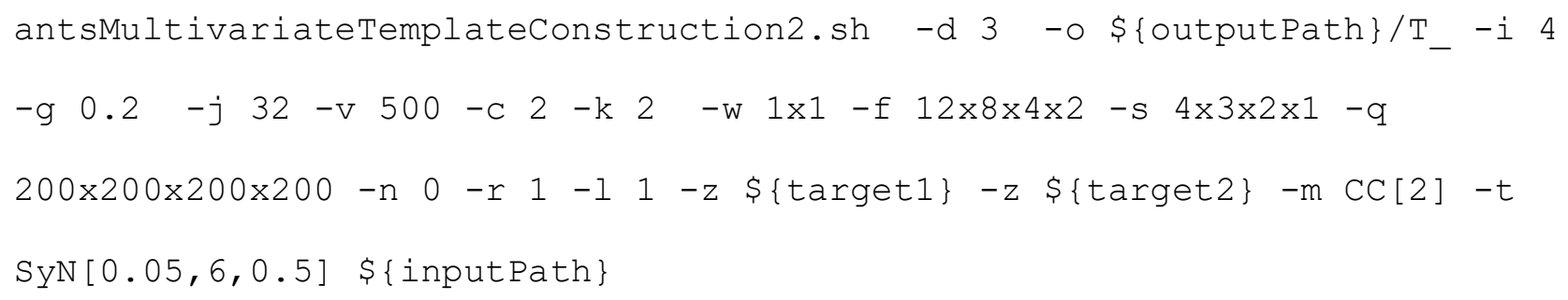


To register the newly generated reference to the mapzebrain coordinate system, we first registered the older Tg(elavl3:H2b-GCaMP6s) average image that existed in mapzebrain (Kunst et al., 2019) onto the newly generated reference and applied the inverse transformation on the newly generated reference image to align to the mapzebrain coordinate system. First, the following ANTs command was used to transform the older mapzebrain $T g($ elavl3:H2b-GCaMP6s) average to new reference:

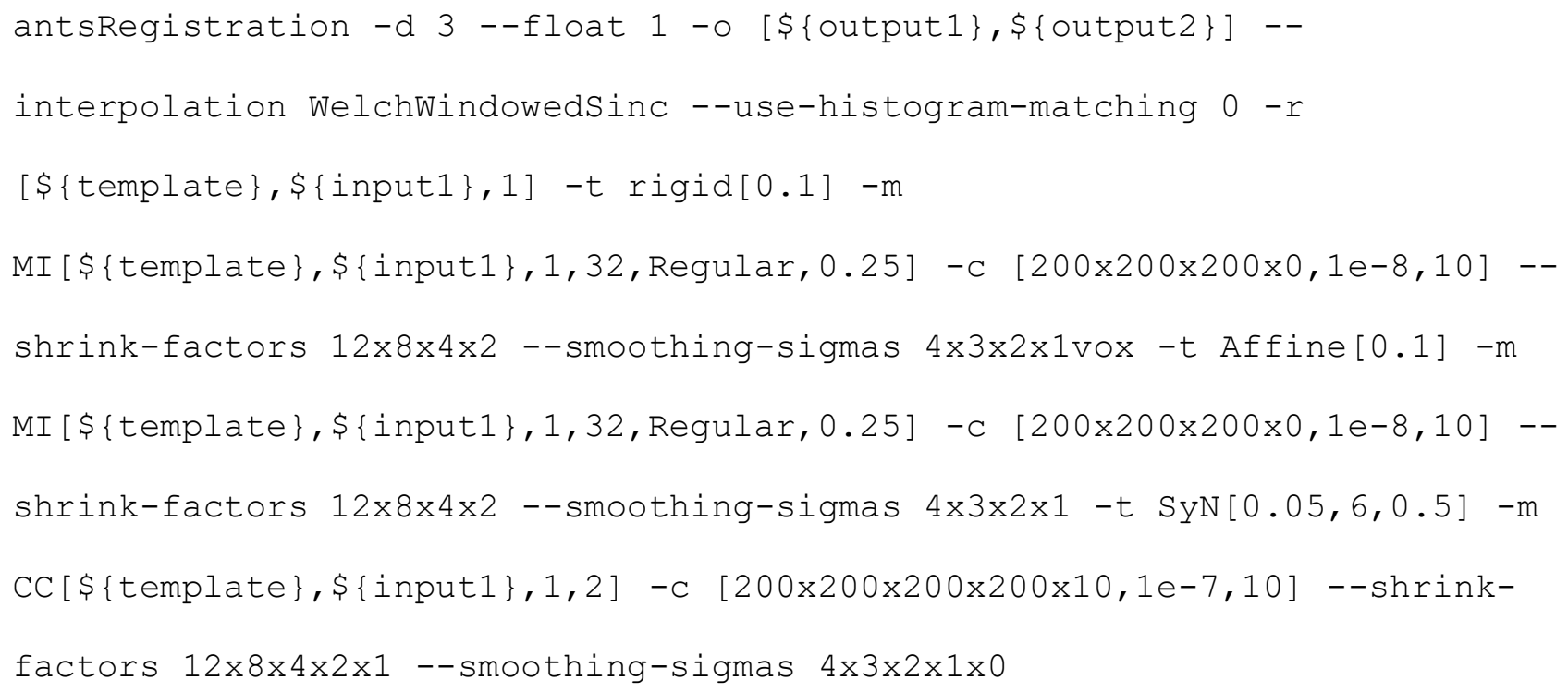

Secondly, inverse transformation was applied on the newly generated reference using the inverse Warp transformation file by running the following ANTs command:

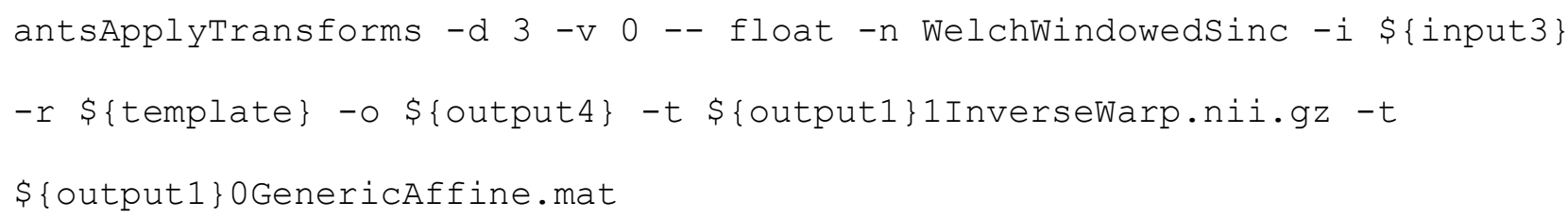

The newly registered reference brain (Supp. Fig. 1 and Suppl. Movie 1) is available to download through the mapzebrain webpage. All the imaged HCR in situ images were registered onto this new reference by registering the Tg(elavl3:H2b-GCaMP6s) image channel using the ANTs command:

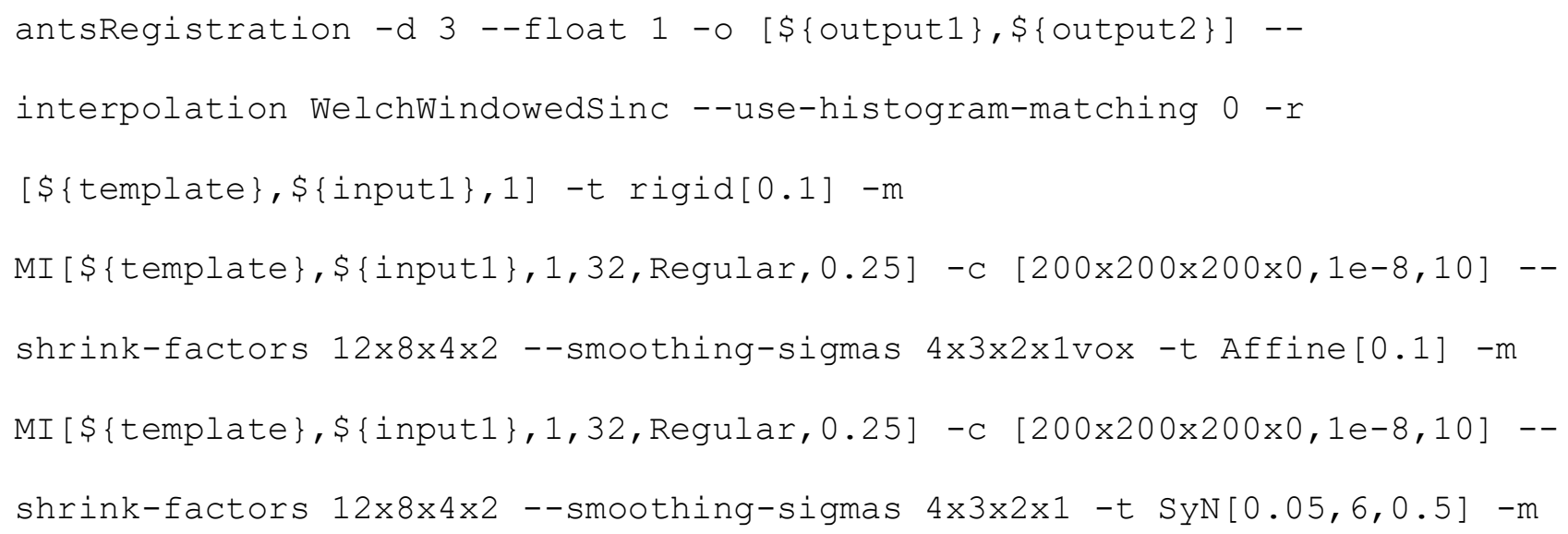


CC $[\$\{$ template $\}, \$\{$ input 1$\}, 1,2]-c[200 \times 200 \times 200 \times 200 \times 10,1 e-7,10]--\operatorname{shrink-}$

factors $12 \times 8 \times 4 \times 2 \times 1$--smoothing-sigmas $4 \times 3 \times 2 \times 1 \times 0$,

followed by applying the transformation files on the HCR image channels using the ANTs command

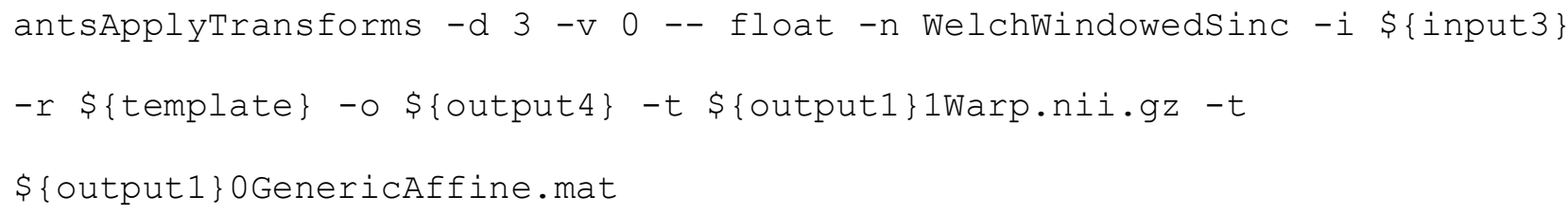

Each HCR-labeled RNA was imaged from three different fish, and registered as described. The three images were then arithmetically averaged using ImageJ (Schneider et al., 2012). Both the average image and the individual registered images are accessible through the mapzebrain site.

\section{cfos FISH experiments}

For $c f o s$ experiments, larvae were raised until $6 \mathrm{dpf}$ under optimal conditions $\left(14 / 10 \mathrm{~h}\right.$ light cycle, $\left.28^{\circ} \mathrm{C}\right)$ in Danieau's solution. At 6 dpf, the larvae were transferred into a 6-well plate, 10 larvae per well until 7 dpf, when they were exposed to different stimuli for $40 \mathrm{~min}$, followed by fixation and HCR staining, as described above. Six fish of each condition were imaged and registered as described before, followed by arithmetical averaging with ImageJ (Schneider et al., 2012). For visualization purposes of the averaged images, the contrast was linearly enhanced. Suppl. Movie 2 anatomical legend was generated using QuPath (Bankhead et al., 2017).

Temperature adaptation: The 6-well plate containing the fish was placed into a water bath set either to $22^{\circ} \mathrm{C}$ or $32^{\circ} \mathrm{C}$ with similar background color for $40 \mathrm{~min}$.

Background adaptation: The 6-well plate containing the fish was placed either on white or black background, at $28^{\circ} \mathrm{C}$ for $40 \mathrm{~min}$.

Prey capture: Paramecia were added into the 6-well plate containing the larvae. Food was not limiting: Many paramecia were still uneaten after $40 \mathrm{~min}$.

Phototaxis: The 6-well plate containing the fish was placed on half-white and half-black background (splitting the well background color equally), at $28^{\circ} \mathrm{C}$ for $40 \mathrm{~min}$.

Looming: Larvae were exposed to black looming disc stimuli using a setup previously described (Larsch and Baier, 2018; Pantoja et al., 2020). Briefly, groups of 10 larvae were placed into a $10 \mathrm{~cm}$ watch glass containing Danieau's solution and left for 2 hours to acclimate to room temperature and white projector illumination from below. For stimulation, expanding black discs were projected to the center of the dish from below. Discs 
expanded linearly from $0-10 \mathrm{~cm}$ diameter within $500 \mathrm{~ms}$, once every 60 seconds. This cycle was repeated over 40 minutes.

Optomotor response: Larvae were exposed to moving gratings using a setup previously described (Larsch and Baier, 2018; Pantoja et al., 2020). Briefly, groups of 10 larvae were placed into a $10 \mathrm{~cm}$ watch glass containing Danieau's solution and left for 2 hours to acclimate to a background of a stationary grating (black/white step grating, $10 \mathrm{~mm}$ spatial frequency) projected from below. After 2 hours, gratings were moved in alternating directions at 1 cycle per second in the following sequence: $15 \mathrm{~s}$ in one direction, $5 \mathrm{~s}$ pause, and $15 \mathrm{~s}$ in the opposite direction. This sequence was repeated over 40 minutes. Visual inspection confirmed a strong behavioral optomotor response under these stimulus conditions. A control group of larvae remained on stationary gratings the entire time.

Alarm substance response: Alarm substance is stored in the club cells of zebrafish epidermis and released upon skin damage. For the experiment, five adult wild-type donor fish were euthanized and scales from both flanks were collected with the blunt side of a sterile razor blade. The scales were washed off with sterile-filtered Danieau's solution and collected in a Falcon tube, avoiding any contamination with blood. The total $20 \mathrm{ml}$ isolate was vortexed, filtered through a Whatman paper, and placed on ice until use. $500 \mu 1$ of the isolate was distributed evenly over the wells of the 6-well plate containing the larvae.

\section{Single neuron morphology clustering}

An ROI surrounding the cerebellar cfos mRNA-labeled area was labeled using the ImageJ segmentation editor plugin. The ROI was then used to search through the mapzebrain platform for neurons whose somas were located within it. 32 neurons were identified, flipped to the left (as described in Kunst et al., 2019), and a morphology similarity score between them was calculated using the NBLAST algorithm (Costa et al., 2016) by applying the nblast_allbyall function implemented in the R package NeuroAnatomy Toolbox (nat) (Bates et al., 2020) with default parameters. Next, unsupervised hierarchical clustering was performed using the nhclust function of the nat package with default parameters, and the results were plotted using the $\mathrm{R}$ packages dendroextras and rgl. The analysis and plotting $\mathrm{R}$ code can be found at (https://github.com/ishainer/Shainer_Kuehn_et_al_2022). 


\section{Funding}

Alexander von Humboldt foundation research fellowship for postdoctoral researchers - I.S

NARSAD Young Investigator Award - J.L

Max Planck Society - H.B

\section{Acknowledgments}

We thank Robert Kasper for microscopy consultation and support, and Krasimir Slanchev, Manuel Stemmer and Mario Wullimann for their input and support with experiments. We thank all members of the Baier lab for beta testing and fruitful discussions.

\section{Competing interests}

The authors declare no competing interests.

\section{References}

Antinucci P, Folgueira M, Bianco IH. 2019. Pretectal neurons control hunting behaviour. Elife 8:e48114.

Avants BB, Tustison NJ, Song G, Cook PA, Klein A, Gee JC. 2011. A reproducible evaluation of ANTs similarity metric performance in brain image registration. Neuroimage 54:2033-2044.

Bae Y-K, Kani S, Shimizu T, Tanabe K, Nojima H, Kimura Y, Higashijima S, Hibi M. 2009. Anatomy of zebrafish cerebellum and screen for mutations affecting its development. Dev Biol 330:406-426.

Bankhead P, Loughrey MB, Fernández JA, Dombrowski Y, McArt DG, Dunne PD, McQuaid S, Gray RT, Murray LJ, Coleman HG. 2017. QuPath: Open source software for digital pathology image analysis. Sci Rep 7:1-7.

Bates AS, Manton JD, Jagannathan SR, Costa M, Schlegel P, Rohlfing T, Jefferis GSXE. 2020. The natverse, a versatile toolbox for combining and analysing neuroanatomical data. Elife 9:e53350.

Brockerhoff SE, Hurley JB, Janssen-Bienhold U, Neuhauss SC, Driever W, Dowling JE. 1995. A behavioral screen for isolating zebrafish mutants with visual system defects. Proc Natl Acad Sci 92:10545-10549.

Chen KH, Boettiger AN, Moffitt JR, Wang S, Zhuang X. 2015. Spatially resolved, highly multiplexed RNA profiling in single cells. Science (80- ) 348 . 
Chen X, Mu Y, Hu Y, Kuan AT, Nikitchenko M, Randlett O, Chen AB, Gavornik JP, Sompolinsky H, Engert F. 2018. Brain-wide organization of neuronal activity and convergent sensorimotor transformations in larval zebrafish. Neuron 100:876-890.

Chia JSM, Wall ES, Wee CL, Rowland TAJ, Cheng R-K, Cheow K, Guillemin K, Jesuthasan S. 2019. Bacteria evoke alarm behaviour in zebrafish. Nat Commun 10:1-13.

Choi HMT, Schwarzkopf M, Fornace ME, Acharya A, Artavanis G, Stegmaier J, Cunha A, Pierce NA. 2018. Third-generation in situ hybridization chain reaction: multiplexed, quantitative, sensitive, versatile, robust. Development 145:dev165753.

Cong L, Wang Z, Chai Y, Hang W, Shang C, Yang W, Bai L, Du J, Wang K, Wen Q. 2017. Rapid whole brain imaging of neural activity in freely behaving larval zebrafish (Danio rerio). Elife 6:e28158.

Cook SJ, Jarrell TA, Brittin CA, Wang Y, Bloniarz AE, Yakovlev MA, Nguyen KCQ, Tang LT-H, Bayer EA, Duerr JS. 2019. Whole-animal connectomes of both Caenorhabditis elegans sexes. Nature 571:63-71.

Costa M, Manton JD, Ostrovsky AD, Prohaska S, Jefferis GSXE. 2016. NBLAST: rapid, sensitive comparison of neuronal structure and construction of neuron family databases. Neuron 91:293-311.

Gahtan E, Tanger P, Baier H. 2005. Visual prey capture in larval zebrafish is controlled by identified reticulospinal neurons downstream of the tectum. J Neurosci 25:9294-9303.

Gong S, Zheng C, Doughty ML, Losos K, Didkovsky N, Schambra UB, Nowak NJ, Joyner A, Leblanc G, Hatten ME. 2003. A gene expression atlas of the central nervous system based on bacterial artificial chromosomes. Nature 425:917-925.

Hawrylycz MJ, Lein ES, Guillozet-Bongaarts AL, Shen EH, Ng L, Miller JA, Van De Lagemaat LN, Smith KA, Ebbert A, Riley ZL. 2012. An anatomically comprehensive atlas of the adult human brain transcriptome. Nature 489:391-399.

Heap L, Goh C-C, Kassahn KS, Scott EK. 2013. Cerebellar output in zebrafish: an analysis of spatial patterns and topography in eurydendroid cell projections. Front Neural Circuits 7:53.

Herrera DG, Robertson HA. 1996. Activation of c-fos in the brain. Prog Neurobiol 50:83-107.

Kappel JM, Slangewal K, Foerster D, Shainer I, Svara F, Januszewski M, Sherman S, Baier H, Larsch J. 2021. Visual recognition of social signals by a tecto-thalamic neural circuit. bioRxiv.

Kenney JW, Steadman PE, Young O, Shi MT, Polanco M, Dubaishi S, Covert K, Mueller T, Frankland PW. 
2021. A 3D adult zebrafish brain atlas (AZBA) for the digital age. Elife 10:e69988.

doi:10.7554/eLife.69988

Kölsch Y, Hahn J, Sappington A, Stemmer M, Fernandes AM, Helmbrecht TO, Lele S, Butrus S, Laurell E, Arnold-Ammer I. 2021. Molecular classification of zebrafish retinal ganglion cells links genes to cell types to behavior. Neuron 109:645-662.

Kovacs KJ. 2008. Measurement of immediate-early gene activation-c-fos and beyond. J Neuroendocrinol 20:665-672.

Kunst M, Laurell E, Mokayes N, Kramer A, Kubo F, Fernandes AM, Förster D, Dal Maschio M, Baier H. 2019. A cellular-resolution atlas of the larval zebrafish brain. Neuron 103:21-38.

Larsch J, Baier H. 2018. Biological motion as an innate perceptual mechanism driving social affiliation. Curr Biol 28:3523-3532.

Lein ES, Hawrylycz MJ, Ao N, Ayres M, Bensinger A, Bernard A, Boe AF, Boguski MS, Brockway KS, Byrnes EJ. 2007. Genome-wide atlas of gene expression in the adult mouse brain. Nature 445:168-176. Lovett-Barron M, Chen R, Bradbury S, Andalman AS, Wagle M, Guo S, Deisseroth K. 2020. Multiple convergent hypothalamus-brainstem circuits drive defensive behavior. Nat Neurosci 23:959-967.

Low AYT, Goldstein N, Gaunt JR, Huang K-P, Zainolabidin N, Yip AKK, Carty JRE, Choi JY, Miller AM, Ho HST. 2021. Reverse-translational identification of a cerebellar satiation network. Nature 1-5. Marquart GD, Tabor KM, Horstick EJ, Brown M, Geoca AK, Polys NF, Nogare DD, Burgess HA. 2017. High-precision registration between zebrafish brain atlases using symmetric diffeomorphic normalization. Gigascience 6:gix056.

Milyaev N, Osumi-Sutherland D, Reeve S, Burton N, Baldock RA, Armstrong JD. 2012. The Virtual Fly Brain browser and query interface. Bioinformatics 28:411-415.

Mueller T, Wullimann M. 2015. Atlas of early zebrafish brain development: a tool for molecular neurogenetics. Academic Press.

Neuhauss SCF, Biehlmaier O, Seeliger MW, Das T, Kohler K, Harris WA, Baier H. 1999. Genetic disorders of vision revealed by a behavioral screen of 400 essential loci in zebrafish. J Neurosci 19:8603-8615. Orger MB, Gahtan E, Muto A, Page-McCaw P, Smear MC, Baier H. 2004. Behavioral screening assays in zebrafish. Methods Cell Biol 77:53-68. 
Orger MB, Smear MC, Anstis SM, Baier H. 2000. Perception of Fourier and non-Fourier motion by larval zebrafish. Nat Neurosci 3:1128-1133.

Ortiz C, Navarro JF, Jurek A, Märtin A, Lundeberg J, Meletis K. 2020. Molecular atlas of the adult mouse brain. Sci Adv 6:eabb3446.

Pantoja C, Larsch J, Laurell E, Marquart G, Kunst M, Baier H. 2020. Rapid effects of selection on brain-wide activity and behavior. Curr Biol 30:3647-3656.

Raj B, Farrell JA, Liu J, El Kholtei J, Carte AN, Acedo JN, Du LY, McKenna A, Relić Đ, Leslie JM. 2020. Emergence of neuronal diversity during vertebrate brain development. Neuron 108:1058-1074.

Randlett O, Wee CL, Naumann EA, Nnaemeka O, Schoppik D, Fitzgerald JE, Portugues R, Lacoste AMB, Riegler C, Engert F. 2015. Whole-brain activity mapping onto a zebrafish brain atlas. Nat Methods 12:1039-1046.

Ronneberger O, Liu K, Rath M, Rue $\beta$ D, Mueller T, Skibbe H, Drayer B, Schmidt T, Filippi A, Nitschke R. 2012. ViBE-Z: a framework for 3D virtual colocalization analysis in zebrafish larval brains. Nat Methods 9:735-742.

Schneider CA, Rasband WS, Eliceiri KW. 2012. NIH Image to ImageJ: 25 years of image analysis. Nat Methods 9:671-675.

Semmelhack JL, Donovan JC, Thiele TR, Kuehn E, Laurell E, Baier H. 2014. A dedicated visual pathway for prey detection in larval zebrafish. Elife $\mathbf{3}$.

Sherman S, Kawakami K, Baier H. 2021. Retinal input influences pace of neurogenesis but not cell-type configuration of the visual forebrain.

Tabor KM, Marquart GD, Hurt C, Smith TS, Geoca AK, Bhandiwad AA, Subedi A, Sinclair JL, Rose HM, Polys NF. 2019. Brain-wide cellular resolution imaging of Cre transgenic zebrafish lines for functional circuit-mapping. Elife 8:e42687.

Temizer I, Donovan JC, Baier H, Semmelhack JL. 2015. A visual pathway for looming-evoked escape in larval zebrafish. Curr Biol 25:1823-1834.

Ukani NH, Yeh C-H, Tomkins A, Zhou Y, Florescu D, Ortiz CL, Huang Y-C, Wang C-T, Turkcan MK, Liu T. 2019. The fruit fly brain observatory: from structure to function. BioRxiv 580290.

Wang F, Flanagan J, Su N, Wang L-C, Bui S, Nielson A, Wu X, Vo H-T, Ma X-J, Luo Y. 2012. RNAscope: a 
bioRxiv preprint doi: https://doi.org/10.1101/2022.02.11.479024; this version posted February 11, 2022. The copyright holder for this

preprint (which was not certified by peer review) is the author/funder, who has granted bioRxiv a license to display the preprint in perpetuity. It is made available under aCC-BY-NC 4.0 International license.

novel in situ RNA analysis platform for formalin-fixed, paraffin-embedded tissues. J Mol diagnostics 14:22-29.

Wee CL, Song EY, Johnson RE, Ailani D, Randlett O, Kim J-Y, Nikitchenko M, Bahl A, Yang C-T, Ahrens MB. 2019. A bidirectional network for appetite control in larval zebrafish. Elife 8:e43775.

Wullimann MF, Rupp B, Reichert H. 1996. The brain of the zebrafish Danio rerio: a neuroanatomical atlasNeuroanatomy of the Zebrafish Brain. Springer. pp. 19-87.

Xu S, Yang H, Menon V, Lemire AL, Wang L, Henry FE, Turaga SC, Sternson SM. 2020. Behavioral state coding by molecularly defined paraventricular hypothalamic cell type ensembles. Science (80- ) 370 .

Yemini E, Lin A, Nejatbakhsh A, Varol E, Sun R, Mena GE, Samuel ADT, Paninski L, Venkatachalam V, Hobert O. 2021. NeuroPAL: a multicolor atlas for Whole-Brain neuronal identification in C. elegans. Cell 184:272-288.

Zhang M, Eichhorn SW, Zingg B, Yao Z, Cotter K, Zeng H, Dong H, Zhuang X. 2021. Spatially resolved cell atlas of the mouse primary motor cortex by MERFISH. Nature 598:137-143.

Zhang Z, Bai L, Cong L, Yu P, Zhang T, Shi W, Li F, Du J, Wang K. 2021. Imaging volumetric dynamics at high speed in mouse and zebrafish brain with confocal light field microscopy. Nat Biotechnol 39:74-83. 
A 29

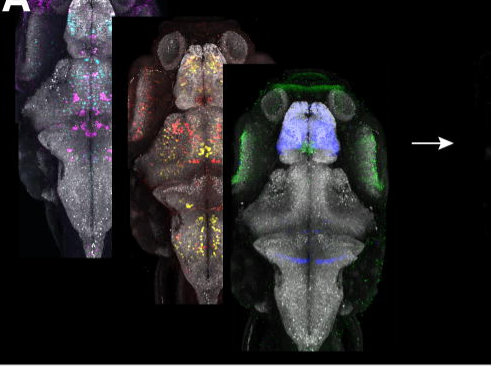

B

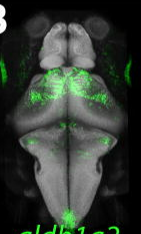

aldh $1 a_{2}$
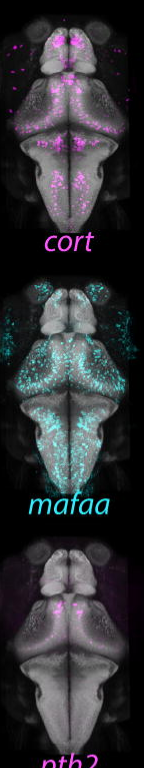

pth2

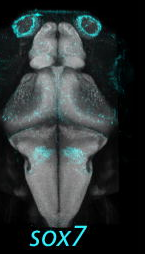

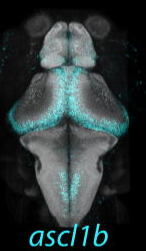
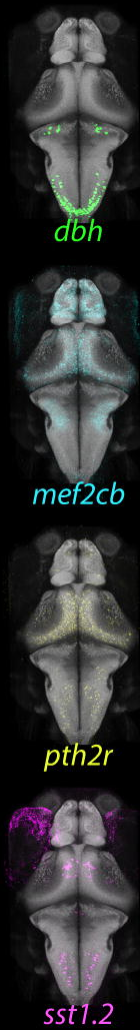
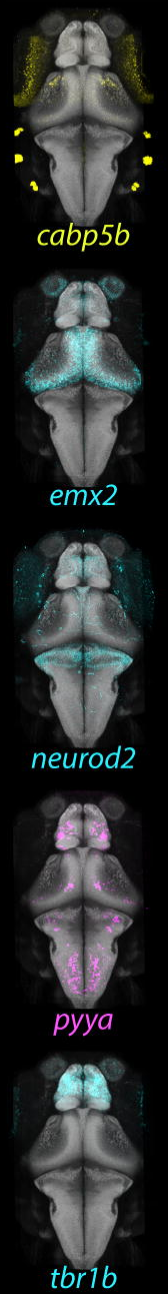

2) mapzebrain

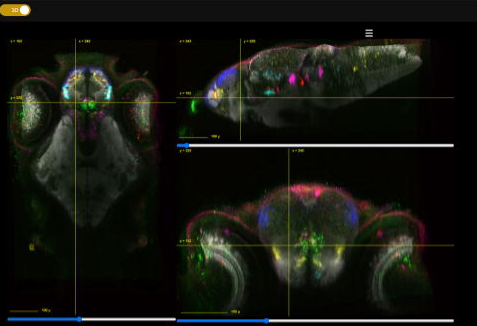

http://fishatlas.neuro.mpg.de/version2
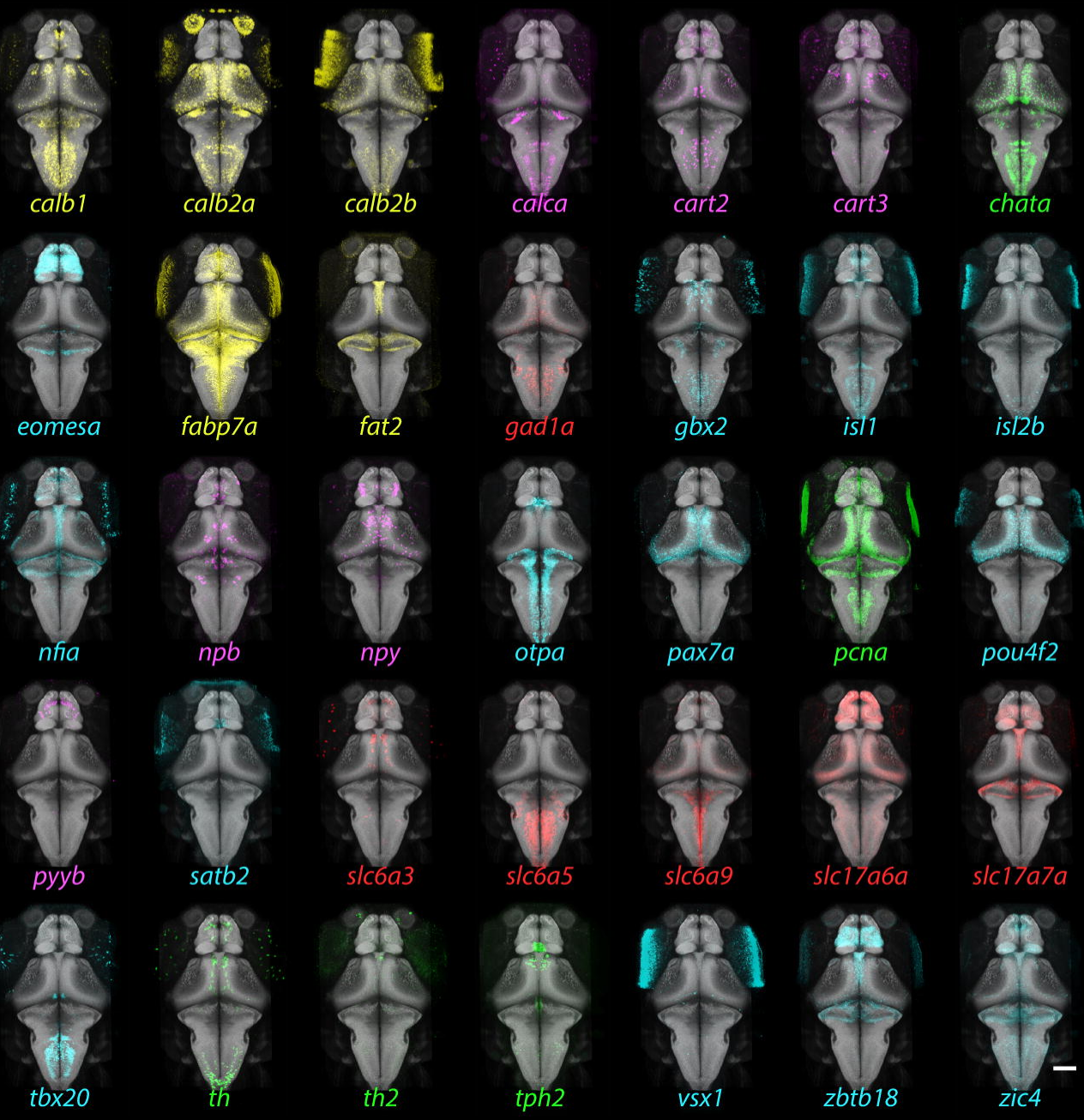


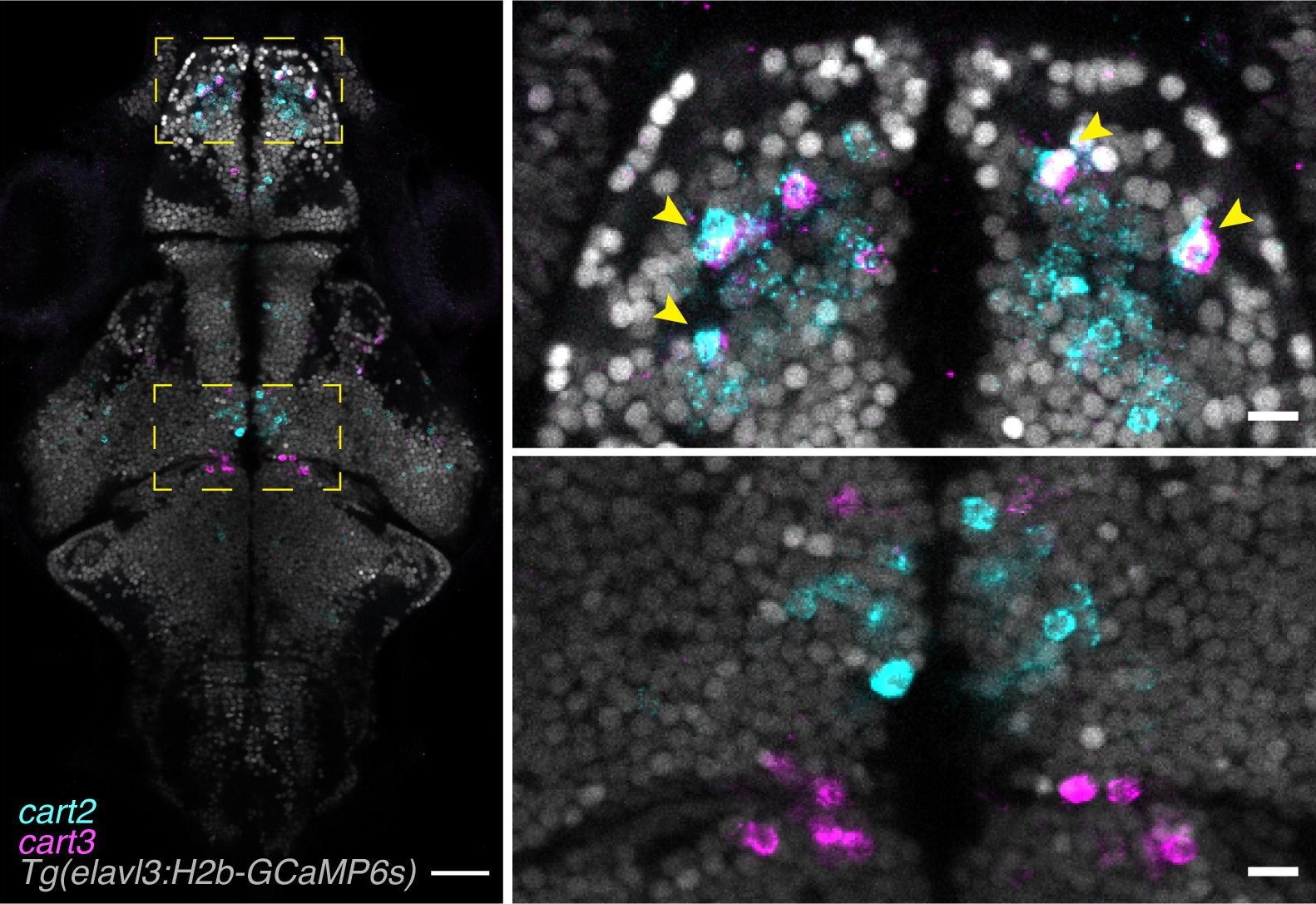




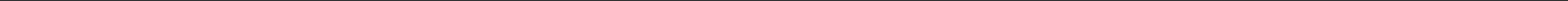




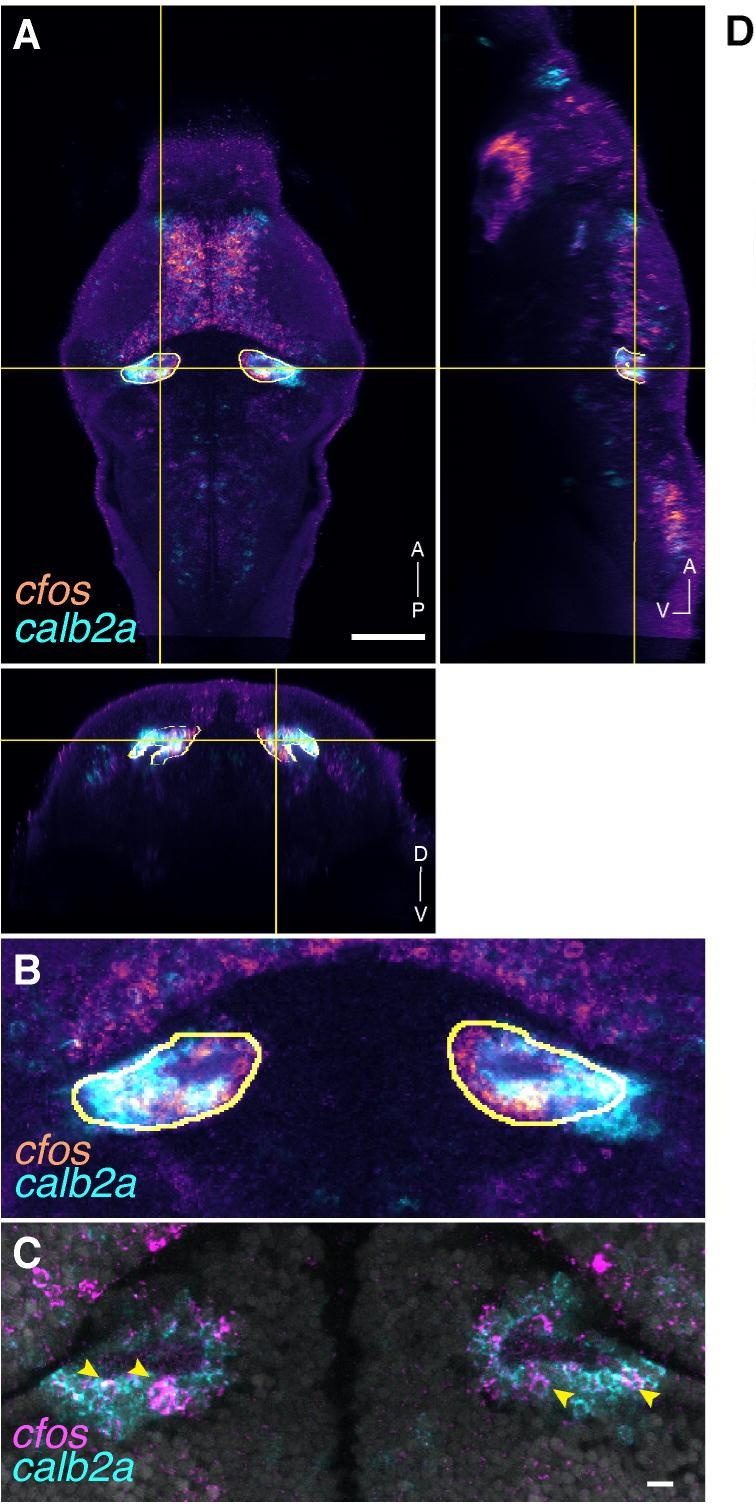

4 .

나
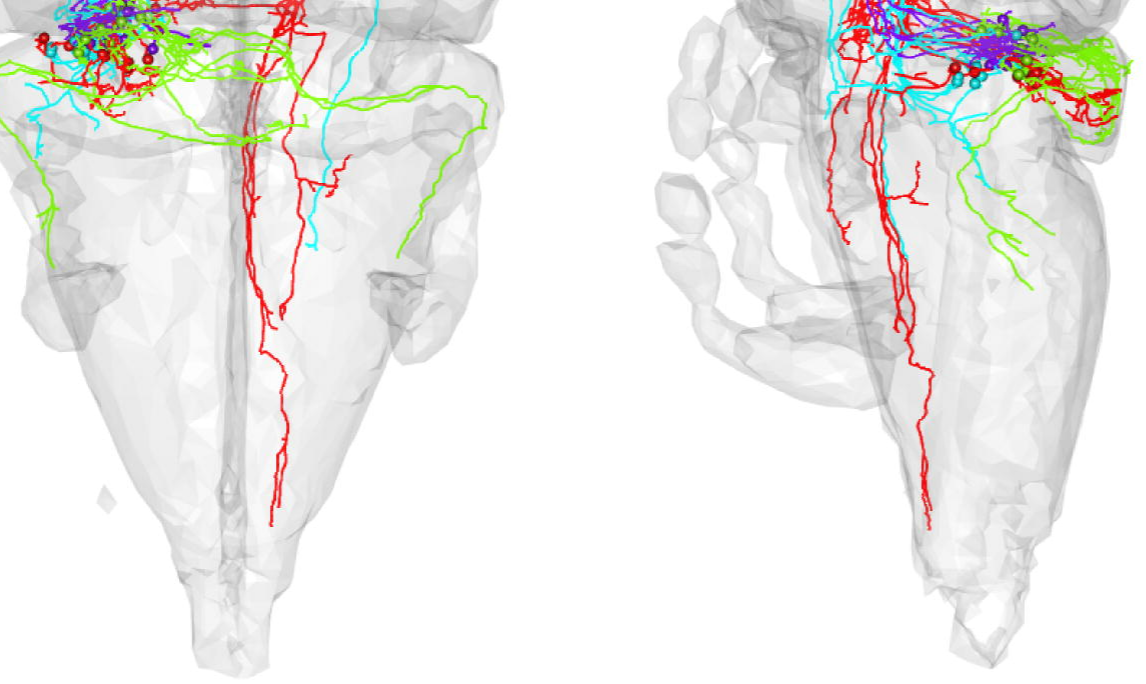

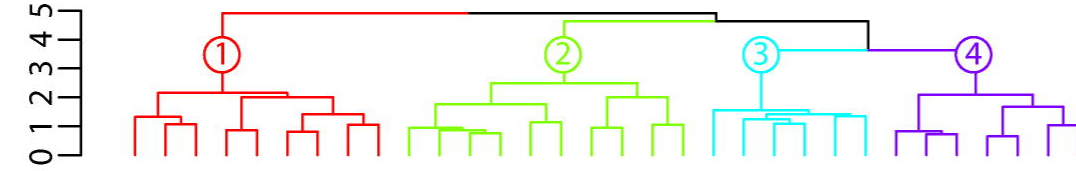
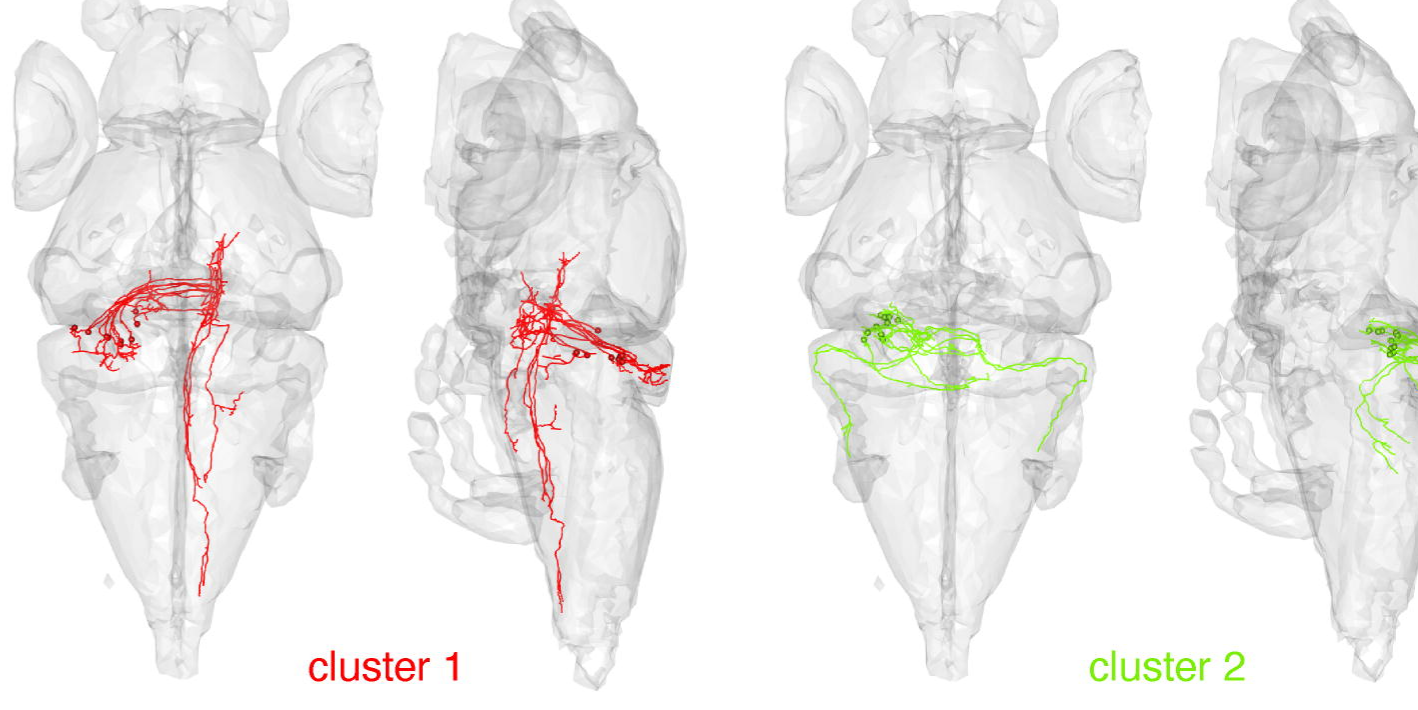

cluster 2
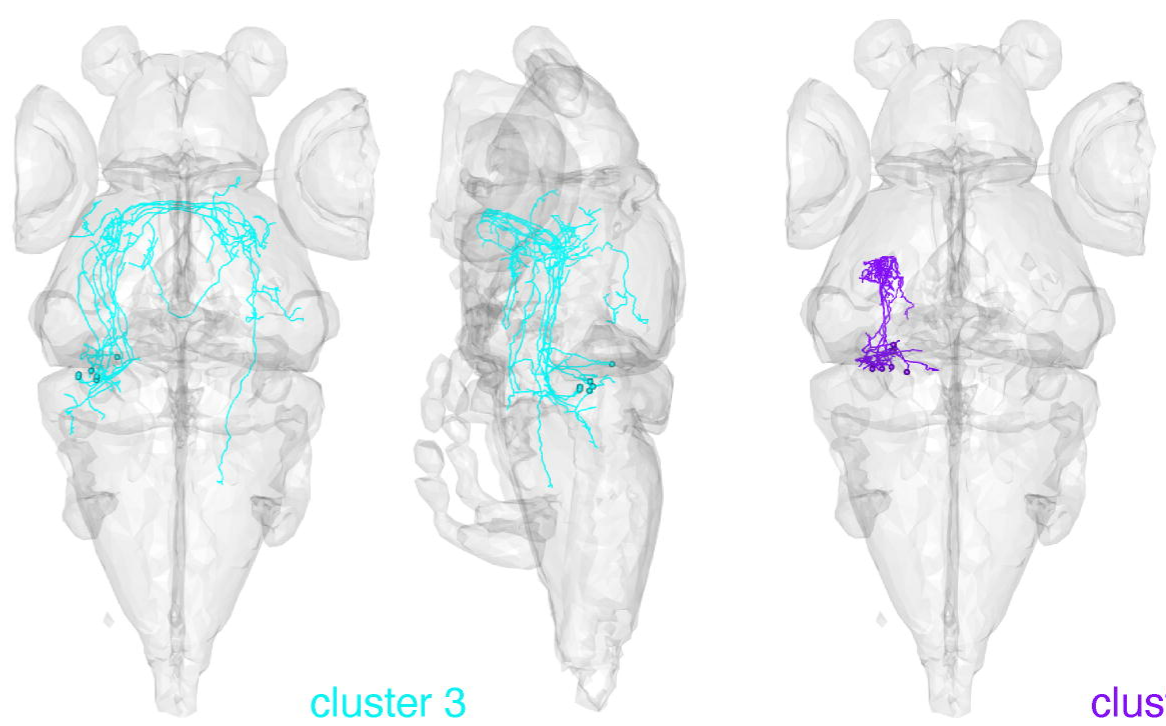

cluster 4

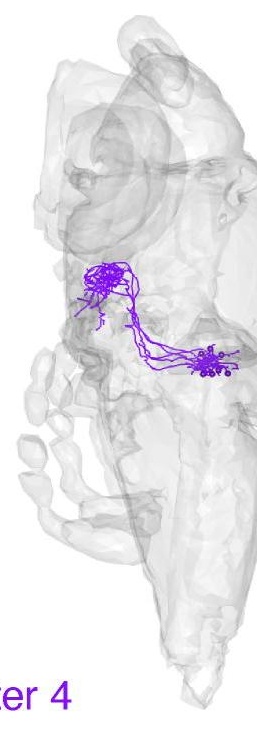

